bevonden. In de bijgevoegde verklaring is apgenomen dat de accountant de aanwezigheid en waarde der vaartuigen niet heeft kunnen vaststellen.

De hypotheekbanken hebben voor een groot deel in hun verslagen nog lange verklaringen, welke min of meer een opsomming geven van wat gedaan is: grossen gezien (,,behoudens die waarvan nog slechts de voorlopige notarisverklaringen konden worden overgelegd"), saldobiljetten verzonden, waarden opgenomen, ingeloste pandbrieven vernietigd, coupons geverifieerd.

In een enkel rapport worden nog opmerkingen gemaakt over samenwerking met de interne-contrôle-afdeling. Wellicht, dat men hier soms een voorbehoud bedoelt; echter is dit dan niet duidelijk vermeld.

In sommige verklaringen worden opmerkingen gemaakt over diverse balansposten (b.v. al of niet gereserveerde belastingen, oorlogsschade, waardering onroerende goederen) welke voor een juiste beoordeling van de balans wel noodzakelijk of gewenst zijn. Het betreft hier geen voorbehouden. $Z_{\mathrm{ij}}$ behoren echter feitelijk thuis in de toelichting van de directie en niet in de accountantsverklaring.

Een toevoeging aan de korte verklaring zonder dat dit een voorbehoud betekent, zal slechts in enkele gevallen gemotiveerd zijn. Dit zijn: 1e. opmerkingen over de contrōle in het buitenland, die de ondertekenende accountant niet zelf heeft kunnen verrichten (is ook geregeld in het Regl. v. Arbeid); 2e. In de verklaring van de Haagse Tramweg Mij. wordt verklaard: „In het bijzonder is nagegaan, dat de stukken zijn vastgesteld met inachtname van de bepalingen der overeenkomst, gesloten tussen de gemeente 's-Gravenhage en de N.V. Haagsche Buurtspoorwegen d.d. .............". Deze toevoeging zal zeer waarschijnlijk speciaal gevraagd zijn en kan dan ook moeilijk vermeden worden.

Tenslotte heb ik onder deze groep nog drie bijzondere gevallen opgenomen. Het eerst betreft een onder beheer staande onderneming. De accountant vermeldt in het betreffende verslag gemotiveerd dat hij geen goedkeurende verklaring kan afgeven. Het tweede betreft een jaarverslag, waarin een volledig accountantsrapport is opgenomen. Het derde geval betrof de Ned. Bank van Zuid-Afrika, waarin een lange verklaring is opgenomen, waarvan de redactie gebonden schijnt te zijn aan de bankwet 1942 van de Unie van Zuid-Âfrika.

WETSONTWERP HOUDENDE DE OPRICHTING VAN EEN INSTITUUT DER BEDRIJFSREVISOREN. INGEDIEND BIJ DE BELGISCHE KAMER DER VOLKSVERTEGENWOORDIGERS ONDER DAGTE. KENING 3 DECEMBER 1947.

\title{
Memorie van toelichting.
}

Sedert geruime tijd doet zich in België de behoefte gevoelen, de vorming van een korps deskundigen te bevorderen, gespecialiseerd in de controle der boekhoudingen van de ondernemingen, in de vorm van een georganiseerd vrij beroep in de aard van de corporaties der ",chartered accountants" of ,,public accountants" die in de Engelssprekende landen sinds lang hun nut hebben bewezen.

Tot de eigenlijke werkkring van de „Bedrijfsrevisoren” zou dus, afgezien van de overige als met hun functie verenigbaar geachte werkzaam- 
heden de taak behoren om de opdrachten uit te voeren, die er toe strekken om de juistheid en de echtheid van de rekening en verantwoording der ondernemingen vast te stellen en echt te verklaren.

Deze opdrachten zouden ze vervullen voor rekening van alle personen of organismen, die door de statuten, een overeenkomst of een wet bevoegd verklaard worden om toezicht uit te laten oefenen op boeken en bescheiden; dergelijke opdrachten zouden hen desgevallend door de openbare besturen kunnen toevertrouwd worden.

Een revisor dient om zijn opdracht, zoals wij deze opvatten behcorlijk te kunnen uitvoeren, navolgende voorwaarden te vervullen:

$1^{\circ}$ hij moet volledig onafhankelijk staan zowel tegenover de leidende elementen der aan zijn toezicht onderworpen organismen als tegenover de beroepsverenigingen of openbare besturen voor wier rekening hij zekere opdrachten kan te vervullen hebben;

$2^{\circ}$ hij dient, in ieder opzicht, persoonlijk aansprakelijk te zijn voor zijn beroepshandelingen; dit wil zeggen dat hij in de wet de middelen niet mag vinden om zijn verantwoordelijkheid te ontduiken, te beperken of op anderen te schuiven;

$3^{\circ}$ hij dient aan strenge criteria wat zijn achtbaarheid betreft te voldoen;

$4^{\circ}$ hij dient deel te maken van een beroepsgroepering dusdanig georganiseerd, dat hare leden aan voorschriften inzake beroepsplichtenleer en -tucht, die streng geformuleerd en stipt toegepast worden, onderworpen wezen;

$5^{\circ}$ hij dient een gespecialiseerde opleiding genoten te hebben, gesteund op een grondige algemene ontwikkeling.

Wanneer de Regering de structuurhervormingen in overweging genomen heeft, die binnen kort het voorwerp van een wetsontwerp zullen uitmaken, leek haar de doelmatigheid van deze hervormingen niet volledig verzekerd, zolang het Rijk niet over een onafhankelijk Bedrijfsrevisorencorps zou beschikken.

Het betreft hier meer in het bijzonder de hervorming die de bedrijfsboekhouding organiseert, de vertegenwoordiging van 's Lands bedrijfsleven instelt, alsmede de oprichting der Ondernemingsraden.

Anderdeels is de instelling van dit Revisorencorps een voorafgaande voorwaarde voor iedere hervorming van de wetgeving op de Handelsvennootschappen, in de betekenis van een doelmatiger bescherming der spaarders.

Om die reden is onderhavig ontwerp volgens de mening van de Regering van zeer dringende aard.

Er zal inderdaad een zekere tijd moeten over heen gaan, vooraleer de wet haar volledige uitwerking zal doen gevoelen.

De rationele organisatie van een Bedrijfsrevisorencorps is niet anders denkbaar dan gegrondvest op een Centraal Organisme, een met rechtspersoonlijkheid bekleed .Instituut", dat even als de orde der advokaten alle personen omvat die wettelijk bevoegd zijn om de titel van ,,bedrijfsrevisor" te voeren.

Aan dit lichaam zouden alle taken dienen toevertrouwd, die met het bestaan en vooral met de handhaving van het beroep verband houden. De wetenschappelijke en praktische opleiding der toekomstige revisoren, het onderzoek van hun bekwaamheden, het hoog houden van de voorschriften betreffende de rechtsschapenheid en de oprechtheid die aan het 
beroep ten grondslag liggen; het bestuderen van alle geschikte middelen om de controle der ondernemingen te verbeteren.

In principe diende de directie van deze instelling uitsluitend aan eigen leden te worden voorbehouden. Men kan evenwel niet over het hoofd zien dat, gelet op de rol die de bedrijfsrevisor ongetwijfeld zal te vervullen krijgen, de patroonsorganisaties en de beroepsverenigingen der werknemers in de leidende organen van het Instituut der Bedrijfsrevisoren zitting hebben. Het spreekt van zelf dat deze vertegenwoordiging niet talrijk hoeft te zijn; het zal volstaan dat de vertegenwoordigers der organismen waarvan sprake, betrokken worden bij het leven en de geleidelijke ontwikkeling van het Instituut.

Anderdeels, gezien alle middens bij een hervorming, als de oprichting van het Instituut der Bedrijfsrevisoren er ongetwijfeld een is, belang hebben, lijkt het niet meer dan logisch dat gedurende enkele jaren er in de leidende organen van het Instituut personaliteiten opgenomen worden. waarop de keuze uitsluitend uit hoofde van hun persoonlijke waarde gevallen is, zelfs indien ze niet tot de leden van het Instituut behoren.

Deze personaliteiten zullen aan de instelling waarborgen bijbrengen van gewetensvolheid, werkkracht en morele onafhankelijkheid. De taak dezer eerste leiders zal er in bestaan de totstandkoming en eerste ontwikkeling van het Instituut der Bedrijfsrevisoren in goede banen te leiden, zulks tot op het ogenblik waarop een traditie zich gevestigd hebbende en de beroepskaders voldoende bezet zijnde, de leden van het Instituut in staat zullen zijn om zich zelf te besturen.

Ongetwijfeld had men de op te richten instelling een benaming kunnen verlenen, waarin de uitdrukking ,accountants" voorkomt. Het leek echter verkieslijker, vermits de leden van het Instituut de enigen dienen te zijn die de titel voeren, die men zinnens is hun te verlenen, geen reeds gebruikte benoeming te bezigen. Het zou niet billijk geweest zijn enig nadeel te berokkenen aan eerzame burgers die thans op wettige wijze ,accountants" genaamd worden en waarvan opleiding en ervaring wellicht ontoereikend zouden zijn om hen toe te laten lid te worden van het Instituut der Bedrijfsrevisoren. Het beroep van Bedrijfsrevisor, zoals wij het opvatten verschilt trouwens, in menig belangrijk punt, helemaal van de bedrij vigheid die thans door de meeste accountants wordt uitgeoefend.

Hoofdstuk 1 behelst de beschikkingen verband houdend met de oprichting van het Instituut, de vaststelling van zijn benaming, de bepaling van zijn doel en de nauwkeurige omlijning van zijn bezittingen.

Het Instituut moet zich niet alleen tot doel stellen er voor te zorgen dat de bedrijfsrevisoren een degelijke opleiding genieten en hun duurzame organisatie te verzekeren, maar tevens dat de beroepswerking zijner leden gesteund en bevorderd en hun beroepsbelangen verdedigd worden. Bovendien krijgt het een wetenschappelijke taak te vervullen namelijk bij te dragen tot de vooruitgang der boekhoudkundige wetenschap en een sociale taak namelijk het zijne bij te dragen tot een verhoogde bescherming van de spaarders. Het zal deze opdracht vervullen door de vraagstukken te bestuderen, die verband houden met het beroep van bedrijfsrevisoren, met het wettelijk statuut der vennootschappen en met de fiscale wetgeving en door de resultaten dezer studiën ter kennis te brengen van de autoriteiten en de bevoegde organismen (art. 2).

Op financieel en administratief gebied zal het Instituut volledig autonoom zijn (art. 3 en 4).

Hoofdstuk II geeft een nadere bepaling van de leden van het Instituut en omschrijft nauwkeurig hun rechten en verplichtingen. 
Het Instituut dient al degene te groeperen die het beroep van Bedrijfs revisor uitoefenen (art. 5).

Derhalve zal het recht deze titel te voeren uitsluitend voorbehouden blijven aan zijn leden (art. 9) en het onrechtmatig gebruik van de hoedanigheid van bedrijfsrevisor wordt als misbedrijf beschouwd (art. 36).

Het ontwerp voorziet twee soorten van leden: werkende leden en gewone leden.

De eigenschap van werkend lid wordt enkel toegekend aan gewone leden met ten minste een bepaald aantal jaren beroepspraktijk. Alleen de werkende leden nemen deel aan het beheer van het Instituut, namelijk door het bijwonen der algemene vergaderingen. Alleen zij kunnen tot lid der raden van het Instituut aangesteld worden. Bovendien is het wenselijk dat in de reglementen van het Instituut voorzien wordt, dat men om werkend lid te kunnen worden hiertoe, de aanvraag dient te doen en hij een aanmerkelijk hogere bijdrage dan de gewone leden wil storten. Deze beschikkingen zullen als gevolg hebben dat het waarnemen van de leiding en de uitoefening van de tucht in het Instituut uitsluitend voorbehouden blijven aan de leden die bestendig de solidariteit en de vooruitgang van het beroep betrachten.

Aan de werkende leden, die opgehouden hebben het beroep van bedrijfsrevisor uit te oefenen, zal de uitsluitend als een eretitel te beschouwen titel van erelid kunnen verleend worden.

De stagedoenden, die de vereiste opleiding nog niet hebben gekregen en het beroep van bedrijfsrevisor nog niet uit oefenen, dienen niet als leden van het Instituut aangezien te worden, alhoewel ze nochtans inzake tucht aan het toezicht van het gezag van het Instituut onderworpen zijn.

De regelmatig bijgewerkte lijst der leden van het Instituut zal door middel van het Staatsblad ter kennis van het publiek gebracht worden.

Om te vermijden, dat de leden van het Instituut zouden gevaar lopen hun onafhankelijkheid in zekere mate te verliezen en ten einde de gewone liefhebbers zonder meer te weren, die zich slechts bij gelegenheid of zo nu en dan op het toezicht der ondernemingen zouden toeleggen, wordt in het ontwerp voorzien, dat de werkende of gewone leden geen andere beroepsbezigheden mogen uitoefenen dan deze van bedrijfsrevisor of deze die uitdrukkelijk door de reglementen worden toegelaten (art. 9).

Anderdeels zijn de revisors evenals al deze, die een vrij beroep uitoefenen, tot het beroepsgeheim gehouden. Het nakomen van deze verplichting, die slechts ophoudt te bestaan wanneer de revisor in rechten dient te getuigen of wanneer hij over een bepaalde opdracht verslag uitbrengt, wordt door strafbepalingen gewaarborgd, die strenger zullen zijn, indien de overtreding begaan werd met bedrieglijk opzet of met het inzicht schade te berokkenen of met het doel er voordeel uit te halen, hetzij voor zich zelf, hetzij ten bate van derden (art. 37).

Bij zijn beroepsopleiding hoeft de bedrijfsrevisor drie stadia te doorlopen:

$\mathrm{Na}$ de stage te hebben doorgemaakt, waarvan de voorwaarden nader bepaald zijn in Hoofdstuk IV van het ontwerp, zal de toekomstige bedrijfsrevisor na in het in artikel 26 voorziene eindexamen geslaagd te zijn, gewoon lid worden. $\mathrm{Hij}_{\mathrm{ij}}$ zal slecht na vijf jaar ononderbroken uitoefening van het beroep de hoedanigheid van werkend lid kunnen verwerven. Aangezien het ingevolge het ontwerp georganiseerd vrij beroep, zoals trouwens de overige vrije beroepen, hoofdzakelijk gegrondvest zijn op de zedelijke kwaliteiten van hen die er zich op toeleggen, dringt de 
voorafgaande eedaflegging zich op met evenveel redenen voor de ondernemingsrevisoren als voor de advokaten.

De mogelijkheid om rechtspersonen en inzonderheid de bureau's van advies in belastingzaken die op het huidig ogenblik bestaan als lid van het Instituut te aanvaarden werd van de hand gewezen. Slechts de natuurlijke personen kunnen werkende of gewone leden van het Instituut worden (art. 8).

Door deze beschikking tracht men te voorkomen, dat, gedekt door geoorloofde vormen, de leden van het Instituut er zich toe laten verleiden hun verantwoordelijkheid of onafhankelijkheid te ontduiken of te beperken.

Verdienste en gezag van het beroep van bedrijfsrevisor dienen uitsluitend te wijten te zijn aan de persoonlijke kwaliteiten der revisoren alsmede aan hun onderlegdheid en ervaring; hun persoonlijke aansprakelijkheid zal de beste waarborg zijn voor de waarde van hun werkzaamheden (art. 11, lid 1).

In het ontwerp wordt de mogelijkheid voorzien voor de bedrijfsrevisoren om zich onderling te verenigen met het oog op de gemeenschappelijke uitoefening van hun beroep.

Er wordt evenwel in voorzien, dat dusdanige vereniging slechts kan toegelaten worden op vooraf aan het toezicht der overheid van het Instituut onderworpen voorwaarden (art. 1, lid 2 en volgende) en er wordt uitdrukkelijk verboden zich te verenigen met personen, die de eigenschap van bedrijfsrevisor niet bezitten. Het zal de bedrijfsrevisoren evenwel vrijstaan met technici wier medewerking hun voor de uitoefening van hun beroep noodzakelijk blijkt, op een andere wijze dan door middel van een vennootschapscontract aan zich te verbinden.

Artikel 5 van het ontwerp voorziet voor de leden de verplichting een jaarlijkse bijdrage te betalen, waarvan het bedrag en de inningsvoorwaarden zullen vasigesteld worden door de reglementen van het Instituut.

Wat de stagedoenden betreft, ligt het niet alleen niet in de bedoeling hun een bijdrage of een opnemingsrecht te doen betalen, maar er is zelfs voorzien hun vergoedingen uit te keren uit een Centrale Kas voor Stagedoenden, die door bijdragen van de leden van het Instituut zal gespijsd worden. Het is trouwens niet meer dan billijk dat jongelui, die zich op de loopbaan van bedrijfsrevisor voor bereiden, gedurende hun proeftijd een vergoeding kunnen ontvangen, indien de inkomsten van het gezin. waartoe ze behoren, zulk een vergoeding wettigen. Anderdeels begrijpt men zonder moeite, dat zelfs indien de stagedoende gedurende de eerste jaren van zijn proeftijd geen enkele dienst aan zijn patroon bewijst, deze laatste nochtans in het belang van zijn beroep, in zijn geheel genomen, zich verplicht moet achten een bijdrage te storten tot steun der stagedoende.

In Hoofdstuk III worden beheer en werking van het Instituut geregeld.

De werking van het Instituut zal door twee hoofdorganen verzekerd worden: de Algemene Vergadering der werkende leden en de Hoge Raad alsmede door met bijzonder opdrachten belaste hulpcolleges: de Proeftijdcommissies en de Tuchtraden.

De tot het verzekeren der werking van het Instituut en ter verwezenlijking van zijn doel nodige reglementen zullen bij koninklijk besluit worden vastgesteld; het betreft hier namelijk het organiek reglement, het huishoudelijk reglement, het proeftijdreglement, het reglement inzake beroepstucht, en het reglement der tuchtraden.

De algemene vergadering zal het hoogste orgaan uitmaken, dat over 
de meest uitgebreide bevoegdheden zal beschikken om beslissingen te nemen en alle daden te stellen die voor het Instituut van belang zijn. terwijl de Hoge Raad het actief element is, dat gelast is initiatieven te nemen en bovendien bekleed is met een eigen bevoegdheid, die in een ruimere zin dient verstaan.

De algemene vergadering zal, in 't bijzonder, als functie hebben, door verkiezing de andere organen aan te duiden. Nochtans worden de voorzitter, de ondervoorzitter en de beide secretarissen benoemd bij koninklijk besluit uit een door de algemene vergadering voor elke functie voor te dragen lijst van drie candidaten.

Zullen eveneens door de Minister, tot wiens bevoegdheid de Economische Zaken behoren, deze leden van de Hoge Raad benoemd worden, die er eensdeels de bedrijfshoofden en anderdeels de beroepsverenigingen der werknemers zullen vertegenwoordigen.

De voorzitter van de Centrale Tuchtraad zal eveneens niet door de algemene vergadering maar door de Hoge Raad benoemd worden. Aangezien de candidaat tot dit ambt niet onder de leden van het Instituut mag gekozen worden, lijkt het inderdaad ongepast diens benoeming in een vrij talrijke vergadering te bespreken, aan wier beraadslagingen een zeker ruchtbaarheid dient gegeven. De voorstellen van de algemene vergadering met het oog op de benoemingen tot de functie van voorzitter, ondervoorzitter en secretarissen van het Instituut alsmede de benoemingen van de andere leden van de Hoge Raad zullen moeten gedaan worden, rekening houdend met de noodzakelijkheid een welafgewogen evenwicht tussen de verschillende streken van het land te bewaren.

Anderdeels heeft de algemene vergadering het recht om de reglementen van het Instituut te wijzigen, doch alleen binnen het raam van de organieke wet en mits het voorbehoud van goedkeuring door de uitvoerende macht. Deze reglementen en de hieraan toegebrachte wijzigingen worclen slechts verplichtend gesteld, nadat tot de door de eerste reglementen nader te bepalen ruchtbaarheid is overgegaan.

Door de reglementen kan een indeling van het land in verschillende gewesten worden voorzien, waarvan zowel het aantal als de grenzen zullen vastgesteld worden. Ingevolge deze beschikking zal het mogelijk zijn tot een bepaalde decentralisatie over te gaan op het ogenblik waarop en in de mate waarin deze laatste nuttig zou blijken te zijn; nochtans zou het de goede werking van het Instituut schaden tijdens diens eerste ontwikkelingsjaren, moest er onmiddellijk tot deze decentralisatie worden over gegaan. Bovendien mag deze decentralisatie geen hinderpaal zijn voor de noodzakelijke eenheid zowel vanuit het standpunt van het beheer van het Instituut als wat de beroepsvorming en de tucht betreft.

De Hoge Raad, die geroepen is om een hoofdrol te spelen, dient een voldoende aantal leden te tellen opdat de verschillende streken van het land er op behoorlijke wijze kunnen in vertegenwoordigd worden.

De Raad zal, behalve uit een voorzitter, een ondervoorzitter en de beide secretarissen, uit 13 door de algemene vergadering verkozen leden en uit zes personen die de werkgevers- en werknemers organisaties vertegenwoordigen bestaan.

Het is wenselijk dat het vcorzitterschap van het Instituut waargenomen worde door een vooraanstaand persoon, niet alleen het vertrouwen genietend van zijn collega's en van de leden, maar tevens van de openbare besturen. Gezien de rol die het Instituut te vervullen zal krijgen in de organisatie van 's Lands bedrijfsleven, ligt het voor de hand dat de benoeming van deze leidende personaliteit aan de uitvoerende macht dient over-

ma b b!z. 150 
gelaten te worden. Deze laatste zal evenwel dienen gekozen te worden uit een lijst van drie door de algemene vergadering voor te dragen werkende leden van het Instituut. Zulks geldt eveneens voor de ondervoorzitter en de beide secretarissen. Deze vier personen zullen voor een vijfjaarlijkse termijn benoemd worden, doch hun mandaat is hernieuwbaar. De overige leden worden voor een termijn van drie jaar gekozen.

Ten einde de vertegenwoordiging der verschillende streken van het land bij de Raad te waarborgen, kan in de reglementen voorzien worden, dat met het oog op de verkiezing van alle leden van de Hoge Raad of van een gedeelte ervan de vergadering per gewest zal stemmen.

De taak van de Hoge Raad heeft een vijfroudig doel:

$1^{\circ}$. Hij zal in de eerste plaats het uitvoerend orgaan zijn, dat gelast wordt de beslissingen van de algemene vergadering door te voeren en het beheer alsmede de werking van het Instituut te verzekeren (art. 16).

$2^{\circ}$. Hij zal beslissen over de aanvragen tot het lidmaatschap alsmede over de aanvragen om toelating tot de proeftijd (art. 8 en 22).

$3^{\circ}$. $\mathrm{H}_{\mathrm{ij}}$ zal een reglementerende bevoegdheid bezitten, die weliswaar ondergeschikt is aan de algemene vergadering, doch hem niettemin in staat zal stellen om een vlugge en rechtstreekse actie aan de dag te leggen in verband met het beroepsleven, hem zal de taak toevertrouwd worden door gepaste beslissingen, de beginselen van rechtschapenheid en correctheid hoog te houden alsmede voor de uitoefening van het beroep van bedrijfsrevisor nodige waarborgen van bevoegdheid in stand te houden.

$4^{\circ}$. De veelzijdige ervaring, die de leden van het Instituut tijdens hun loopbaan zullen opdoen, laat toe er een adviserend organisme van te maken dat in samenwerking met de overheid een belangrijke taak zal te vervullen krijgen, de Hoge Raad zal het recht bezitten om aan de openbare machten adviezen te verstrekken of moties over te maken betreffende de organisatie van het beroep, het wettelijk statuut der vennootschappen en de fiskale wetgeving.

$5^{\circ}$. Ten slotte zal de Hoge Raad de bevoegdheid bezitten om in hoger beroep tuchtstraffen op te leggen; іеdег hoger beroep tegen de beslissingen der tuchtraden dient bij hem aanhanging te worden gemaakt. In dit laatste geval zal de Hoge Raad door een door de Minister van Justitie aangewezen magistraat worden voorgezeten (art. 32).

De opleiding der toekomstige revisoren en de handhaving der beroepstucht vereisen de oprichting bij het Institut van twee vaste organisaties aan wie twee belangrijke taken dienen te worden toevertrouwd.

De beroepsopleiding der toekomstige leden zal geschieden onder toezicht van de Centrale Proeftijdcommissie. Deze zal voor de inrichting van de beroepsopleiding zorg dragen en over de stagedoenden toezicht uitoefenen.

Gewestelijke Proeftijd Commissies zullen kunnen opgericht worden indien de behoefte hiertoe zich zou laten gevoelen. Door de reglementen zullen wijze van aanwerving en bevoegdheid van deze gewestelijke Commissies nader bepaald worden.

De oprichting dezer gewestelijke Commissies mag evenwel niet schaden aan de éénheid van leiding bij de beroepsopleiding; de beslissingen van deze gewestelijke Commissies behoeven om geldig te zijn door de Centrale Commissie bekrachtigd te worden.

De centrale tuchtraad is belast met de handhaving van de tucht. $Z_{i j n}$ werking inzake tucht strekt zich niet alleen tot de leden van het Instituut, maar tevens tot de stagedoenden uit. Terzake zullen eveneens geweste- 
lijke tuchtraden kunnen ingesteld worden, maar zoals bij de gewestelijke Proeftijd Commissies zullen hun beslissingen slechts na bekrachtiging door de Hoofdraad rechtsgeldig zijn.

Het spreekt van zelf dat de functie van voorzitter, ondervoorzitter, secretarissen en leden van de Hoge Raad, van het uitvoerend Comité, van de Proeftijdcommissies en van de Tuchtraden kosteloos worden uitgeoefend. Het vervullen dezer functies welke moeten uitgeoefend worden door leden van het Instituut is terzelfdertijd een eer en een beroepsplicht. Er mag derhalve geen enkel materieel voordeel aan verbonden zijn. Bijgevolg kan slechts van vergoedingen sprake zijn bij buitenstaanders, wier taak het is de Tuchtraad of de Hoge Raad zetelende in Tuchtzaken voor te zitten.

Hoofdstuk IV behelst de beschikkingen betreffende de beroepsopleiding der bedrijfsrevisoren.

De opleiding der toekomstige revisoren zal gebeuren onder de bescherming van de Proeftijd Commissie.

De proeftijd moet niet alleen aan de stagedoenden toelaten de voor de uitoefening van het beroep, noodzakelijke zedelijke en technische opleiding zowel practisch als theoretisch te verwerven; hij moet ook toelaten de candidaten uit te schakelen die niet zouden bewezen hebben dat zij de vereiste hoedanigheden bezitten om het beroep eervol en deskundig uit te oefenen.

De proeftijd gaat aan het eindexamen vooraf; deze beschikking beantwoordt aan verschillende bekommernissen, meer inzonderheid:

a) Aan het feit dat de zedelijke kenmerken tot deze behoren die het meeste gewicht in de weegschaal dienen te leggen bij de aanwerving en de uitverkiezing der candidaten; de zedelijke kwaliteiten dezer laatsten zullen gemakkelijker aan de dag treden tijdens een lange proeftijd dan bij de examens.

Het is ongepast dat de technische opleiding noodzakelijk voor de bedrijfsrevisoren zou verleend en officieel erkend worden aan personen die in zedelijk oogpunt voor de uitoefening van het beroep ongeschikt zouden blijken.

b) Aangezien de proeftijd van lange duur dient te zijn en dat de studiën over verscheidene jaren ingedeeld worden, is het wenselijk dat èn proeftijd èn studiën gelijktijdig plaats vinden, zodat vermeden wordt dat voor de opleiding der revisoren zoveel jaren vereist zijn, dat hierdoor een aanzienlijk aantal candidaten zou afgeschrikt worden.

$\mathrm{Om}$ tot de proeftijd toegelaten te worden zal de candidaat die door een peter aangenomen is, die minstens vijf jaar praktijk telt en werkend of aangesloten lid is van het Instituut, aan de Proeftijdcommissie de overeenkomst moeten onderwerpen die hij met zijn peter gesloten heeft. Deze overeenkomst zal de wederzijdse verplichtingen van peter en stagedoende nader omschrijven. Vervolgens dient hij te slagen in een toelatingsexamen, waarvan het programma derwijze opgevat is dat het toelaat er zich rekenschap van te geven of de candidaat behalve de algemene ontwikkeling, die door het middelbaar onderwijs van de hogere graad kan verworven worden, tevens de rijpheid van geest en de vastheid van karakter bezit, die voor zijn beroepsopleiding onmisbaar zijn.

$\mathrm{Om}$ de wetenschappelijke vorming van de stagedoenden te verzekeren kan er geen sprake zijn, door het Instituut een volledig onderwijs te doen organiseren, dat in ruime mate een onnodige herhaling zou zijn van datgene verschaft door de instellingen voor hoger onderwijs, de instellingen voor technisch onderwijs en zekere bestaande beroepsverenigingen. Tij- 
dens zijn proeftijd en zulks is een door de wet ingevoerde nieuwigheid, dient de stagedoende twee examens af te leggen, een candidaats- en een eindexamen.

Elk dezer examens omvat twee proeven. Een theoretische, die voor de Officiële Centrale Jury zal worden afgelegd en slaande op vakken gekozen onder dezen voorzien voor het verwerven van de graad, hetzij van Candidaat in de Handelswetenschappen (voor het Candidatuurexamen), hetzij voor het verwerven van de graad van Licentiaat in Handels- en Financiële Wetenschappen, van Licentiaat in Economische Wetenschappen of van Handelsingenieur (voor het eindexamen).

De andere, practische proef, afgelegd voor een jury samengesteld uit professors en Bedrijfsrevisoren zal gaan over de toepassingen in het arbeidsveld van de Bedrijfsrevisor, der theoretische beginselen die het voorwerp uitmaakten van de proef afgelegd voor de Centrale Jury.

Zoals het in de praktijk in Engeland toegepast wordt voor de examens die de "Chartered Accountants" moeten afleggen, zou door het Instituut een zekere publiciteit kunnen gegeven worden aan de vragen die door de jury's bestaande uit professoren en technici, gesteld worden, om aldus aan de onderwijsinstellingen, waar de stagedoenden lessen volgen, toe te laten hun programma aan te passen en aan hun leerlingen een betere voorbereiding te verzekeren tot de practische proeven georganiseerd door het Instituut.

Het beroep van Bedrijfsrevisor moet niet uitsluitend voorbehouden blijven aan de houders van universitaire diploma's. Het is nochtans rechtvaardig dat deze laatsten zouden vrijgesteld worden van het toelatingsexamen en dat zij zouden genieten van een vermindering van de proeftijd, minstens overeenstemmend met het aantal jaren nodig tot het verwerven van het diploma van Licenciaat in de Handels- en Financiële Wetenschappen, van Licentiaat in Economische Wetenschappen en van Handelsingenieur.

De doeltreffendheid van de proeftijd, de vlijt van de stagedoenden en de bijstand van hun peter zal door de Proeftijdcommissie worden nagegaan.

$\mathrm{Om}$ te voorkomen dat de leden van het Instituut wegens het te groot aantal stagedoenden de beroepsplicht en -taak, er in bestaande nieuwe leden op te leiden, niet behoorlijk zouden vervullen, wordt het aantal stagedoenden, waarvoor een lid van het Instituut te gelijker tijd het peterschap mag op zich nemen, beperkt.

De praktische opleiding onder toezicht van de peter is immers een wezenlijk bestanddeel van de proeftijd; derhalve zal ze slechts doeltreffend zijn wanneer de stagedoende actief aan de beroepsbezigheden deelneemt; de peter moet hem dus hiertoe de gelegenheid bieden.

In de beschikkingen van Hoofdstuk $\mathrm{V}$ wordt de beroepstucht behandeld.

Deze vergen geen nadere verklaring. De in het ontwerp nader omschreven tuchtstraffen worden door de tuchtraden toegepast. De rechtspleging wordt normaal door de bevoegde raad, hetzij ambtshalve, hetzij op klacht van de betrokkene ingesteld. $Z_{i j}$ kan ook ingesteld worden op schriftelijke vordering van een Procureur-generaal bij een Hof van Beroep.

Het optreden van deze hoge magistraat is immers noodzakelijk gebleken om toe te laten bij de tuchtraden zware vergrijpen aanhangig te maken, die ter kennis van de parketten zouden worden gebracht.

Het toezicht van het parket generaal werd op een gelijkaardige wijze voorzien als deze waarop dit in tuchtzaken bij de balie ingericht is. 
Nochtans, daar het beroep tegen de beslissingen der tuchtraden niet bij het Hof van Beroep aanhangig wordt gemaakt, maar wel bij de Hoge Raad, in dit geval voorgezeten door een magistraat, zoals voorzien in artikel 32, zal de tussenkomst van de Procureur generaal zich beperken tot het inzenden van een memorie die zijn met redenen omkleed advies bevat.

Hoofdstuk VII bevat de strafbepalingen bestemd om, zoals bereids gezegd is het wederrechtelijk voeren van de titel van Bedrijfsrevisor en de schending van het beroepsgeheim te bestraffen.

Ten slotte zijn de overgangsbepalingen vervat in Hoofdstuk VIII.

Hoe het Instituut op gang brengen?

Ziedaar een vraagstuk van doorslaggevend belang want van de oplossing ervan hangt het lot, dat aan de hervorming zal beschoren zijn, af. En tevens wat voor een moeilijk op te lossen vraagstuk, vermits het in dit stadium gaat, om te vertrekken van het nulpunt.

Twee moeilijkheden moeten overwonnen worden, de aanwerving der eerste leden en der eerste leiders van het Instituut.

Voor de tweede moeilijkheid is de beste en de eenvoudigste oplossing aan de Koning de macht toe te verirouwen voor een termijn van vijf jaar de leden van de eerste Hoge Raad van het Instituut te benoemen. Deze eerste Raad dient met de meeste zorg te worden samengesteld, hij zal bestaan uit personaliteiten uit alle middens, die bij het beroep waarvan sprake betrokken zijn en die in staat zijn op grond van hun kennis en ervaring een daadwerkelijke bijdrage te leveren tot het te verwezenlijken werk, zoals zakenlieden de personen vertegenwoordigend, die in aanmerking komen om gebruik te maken van de diensten van de bedrijfsrevisoren, deskundigen, de bedrijfsrevisoren vertegenwoordigend, rechtsgeleerden. die belangstellen in de ingevoerde hervorming.

Het lijkt evenwel niet wenselijk er vertegenwoordigers van bestaande bedrijfsorganisaties als dusdanig in op te nemen wegens het gevaar dat ze zouden kunnen lopen de wachtwoorden te moeten involgen, die door hun in vergadering bijeengekomen groepering zouden worden gegeven.

Ten slotte dient bij de samenstelling van de eerste Raad eveneens rekening gehouden met de dubbele noodzakelijkheid een vertegenwoordiging der verschillende gewesten van het land alsmede een billijk evenwicht op taalgebied te verzekeren. Daar het noodzakelijk lijkt, dat de Hoge Raad onder zijn leden ten spoedigste een meerderheid van bedrijfsrevisoren zou bevatten om de overgang te vormen tussen de eerste Raad en de Raad die zal samengesteld worden overeenkomstig hetgene in artikel 15 voorzien is, zal de eerste Raad vóór het verstrijken van het derde jaar, ingaande op de datum van zijn aanstelling, aan de koninklijke goedkeuring de benoeming van acht bijkomende leden moeten voorleggen, deze laatste gewone of werkende leden zijnde van het Instituut. Aldus zullen de bedrijfsrevisoren uiterlijk drie jaar na de instelling van het Instituut met vrij grote zekerheid de meerderheid uitmaken van de Hoge Raad en zal deze laatste op het einde van de overgangsperiode uitsluitend uit bedrijfsrevisoren zijn samengesteld.

Tijdens deze overgangstijd kon de leiding van het Instituut vanzelfsprekend niet toevertrouwd worden aan de leden zelf; inderdaad, op een enigszins willekeurige wijze aangeworven en tot verschillende middens behorend, zouden ze ongetwijfeld in het algemeen geen juiste opvatting hebben van het te verwezenlijken doel en gevaar lopen de instelling van hun normaal doel te doen afwiiken of alleen maar er geen voldoend krachtig impuls aan te geven.

ma b blz. 154 
Het blijkt ook onontbeerlijk tijdens deze periode aan de eerste hogere raad - gelast met het geven van de eerste impuls - al de machten toe te vertrouwen die later zullen uitgeoefend worden door de algemene vergadering der leden.

Tijdens hetzelfde tijdsbestek zal de Centrale Tuchtraad waarin in afwijking van artikel 19, leden van de Hoge Raad opgenomen kunnen worden, in eerste en laatste aanleg beslissen. Gedurende de inrichtingsperiode van het Instituut lijkt het immers moeilijk een Centrale Tuchtraad samen te stellen, bestaande uit leden die aan het beheer van het Instituut geen deel nemen: de beginselen van de beroepsplichtenleer moeten niet alleen bepaald worden door de reglementen, welke door de Raad zullen worden opgesteld, maar tevens nader omschreven door de uitspraken welke in tuchtzaken zullen geveld worden.

Dank zij deze concentratie der bevoegdheden zal een volmaakte éénheid van opvatting bij deze "voortgezette" oprichting van het Instituut voorzitten.

De Hoge Raad zal naar gelang de behoeften zich hiertoe laten gevoelen, de passende reglementen vaststellen; zo zal hij de inrichting van de proeftijd alsmede de opleiding der nieuwe candidaten verder uitwerken; hij zal rechtstreeks waken over het naleven van de beroepsregelen en over de tucht; zijn leden die volkomen bewust zullen zijn van het te bereiken doel, zullen voor het hoogste welzijn der toekomstige revisoren, de beginselen kunnen formuleren die de grondslag dienen te blijven van het beroep.

De tweede bij de aanvang van de werking van het Instituut te overwinnen moeilijkheid zal in de aanwerving der eerste leden bestaan. Om te vermijden dat de eerste aanwerving te empirisch zou gebeuren bepaald artikel 41 de voorwaarden die zullen moeten vervuld worden door de personen die hun toelating als werkend of toegetreden lid zullen aanvragen. De Hoge Raad die over de aanvragen on opneming uitspraak zal doen, zal er zorg voor dragen, dat slechts dezen worden opgenomen, die zowel de nodige theoretische kennis als de vereiste praktische ervaring bezitten en alle gewenste zedelijke waarborgen bieden.

De Minister van Economische Zaken en Middenstand. J. DUVIEUSART.

\section{BOEKBESPREKING}

Dr. Ir. H. G. van Beusekom: De Volkshuisvesting, Serie „De Neder landse Vollsshuishouding tussen twee wereldoorlogen", Uitgeverij "Het Spectrum", Utrechi-Brussel z.j.

door Drs. H. van der Weyde

De leiders van de serie „De Nederlandse Volkshuishouding tussen twee wereldoorlogen" hebben gelijk gehad, dat zij een afzonderlijk deel aan de volkshuisvesting hebben gewijd. Dit belangrijke onderdeel van de menselijke verzorging toch heeft in de periode tussen 1918 en 1940 grote moeilijkheden opgeleverd en tot een kostbare en veelzijdige overheidsbemoeiing aanleiding gegeven, terwij1 het in ditzelfde tijdvak tegenstellingen vertoont van een acute nood enerzijds tot een sterk overschot anderzijds, al was dat laatste dan ook niet algemeen.

De Heer van Beusekom, onze eerste hoogleraar in de volkshuisvesting

m a b blz. 155 